\title{
The Implementation of Dynamic System Theory and the Principles of Growth in Physical Education of Elementary School
}

\author{
Syahrial Bakhtiar ${ }^{1}$ \\ ${ }^{1}$ Universitas Negeri Padang, Indonesia \\ Correspondence: Syahrial Bakhtiar, Universitas Negeri Padang, Indonesia. E-mail: syal_fik@yahoo.com
}

Received: August 1, 2013 Accepted: August 16, 2013 Online Published: August 30, 2013

doi:10.5539/ass.v9n12p105

URL: http://dx.doi.org/10.5539/ass.v9n12p105

\begin{abstract}
Physical education in elementary school is supposed to promote child growth and development, not only for psychomotor, but also within the cognitive and affective domains. The rate of growth and development of children varies from individual to individual. An appropriate program and lesson plan should not be designed based on the level in elementary school only, but it also should rely on individual development. The four principles of growth; cephalocaudal, proximodistal, hierarchical integration and the independence system principle, provide a direction to begin and to end the physical education program or lesson plans. Moreover, dynamic system theory is an essential guidance for designing a developmentally appropriate program in physical education for elementary school students. This theory depicts well how to progress the lesson plan based on child growth and development principles. By understanding both theory and principles, it is expected that flaws in the physical education activities can be avoided in the hope of encouraging physical activity among children.
\end{abstract}

Keywords: dynamic system theory, principle of growth, motor skill program, physical education

\section{Introduction}

Data from the Ministry of Youth and Sports of Indonesia (2010) showed that based on a survey in 2009, a majority of Indonesia population prefer doing exercise only once a week and only $26.7 \%$ of the population exercise 2-4 times a week. Moreover, half of the participants in the survey took advantage of doing exercise during school time. Another shocking data is only $6.8 \%$ of the population is engaged in sports for achievement. Viewed from the type of exercise, the most favorite exercise among the population is jogging $(13.7 \%)$, even though it is a small number, and also in a short duration of exercise, which is less than one hour. This data is a warning in an attempt to prevent society from being in a worse situation related to their health and physical fitness. In terms of achievement in sports, the small percentage of population's eagerness in participating in sports for some reasons answers the gradual decline of sports achievement of Indonesia over the last 10 years. However, considering the tendency of doing exercise during school time, thus it is beneficial for the government to pick up this issue and catch up Indonesia's goal and achievement in health and sports.

School is an advantageous start point for Indonesia to improve sports engagement and physical activities among the population, but it also caution Indonesia to ensure the quality of physical education lesson from kindergarten to high schools. It is known generally that young childhood is an essential age for building their psychomotor, cognitive and affective domain. In term of psychomotor domain, if children are used to perform skills not in the right way, it is more difficult to teach them to be better (Gallahue, 1987). It is known worldwide that it is easier to teach unlearn people than correct their mistake. Therefore, physical education curriculum should be a priority for being examined because the fate of sports achievement, population's health and fitness of Indonesia are determined by physical education at schools. When young children receive beneficial experiences during elementary school time, it will be more likely for them to participate in sports while they are in adolescence or adult age, or even be physically active throughout their life. Because of this reasons, implementing the development in scientific evidences is believed as a bolster for improving the experiences of children related to sports and physical activities.

Many researches have been conducted in order to find enough scientific evidences about sports and physical activities for children, adolescence and adult. Allender, Cowburn and Foster (2006) claim that one reason of less adult being engaged in sports or physical activities is because of lacking in confidence and competence in motor skills. Some studies also have reported that motor skill competences contribute to physical activities for children, 
adolescence and adult (Barnett, Van, Morgan, Brooks \& Beard, 2008; Hands, 2009; and Stodden, Goodway, Langendorfer, Roberton, Rudisill, Garcia, \& Garcia, 2008). Object control skills, as a component of fundamental motor skills, are responsible for moderate to vigorous physical activity (MVPA) (Barnett, Morgan, Ball, \& Lubans, 2011), which lead to being physically active and improve one's health related physical fitness. Regarding the essential of motor skill competence, many research have implemented various motor skill program to children in different approaches, such as direct instructional (Goodway \& Branta 2003; Goodway, Crowe, \& Branta, 2003; Goodway \& Rudisill, 1996), mastery motivational climate (Martin, Rudisill, \& Hastie, 2009; Valentini \& Rudisill, 2004), community program (Draper, Achmat, Forbes, \& Lambert, 2012), and parent-assisted instruction (Hamilton, Goodway, \& Haubenstricker, 1999). However, since data from the Ministry of Youth and Sports of Indonesia reveals that more population spend more time doing exercise in school, it would be more beneficial for analyzing the motor skill program in school settings in order to improve children's motor skills competence and sport achievement. Thus, the purpose of this study is to describe basic principles of designing an appropriate motor skill program for school settings in hope to improve children motor proficiency and their motivation to participate in sports.

\section{Dynamic System Approach for Motor Skill Program}

Reviewing physical education curriculum for elementary schools to high schools in Indonesia found that programs have been designed based on the academic year (equal with age of children). Even, most elementary schools have physical education program based on sports related movement for elementary students. These circumstances are a misconception due to lack understanding of children motor development. Hence, understanding Dynamic System Theory could help in reviewing the physical education curriculum. Dynamic System explains that motor development follows dynamic and system concept. This theory claims that motor development does not depend on age, yet it is related to age. (Gallahue, Ozmun \& Goodway, 2012). It means that age cannot be an absolute standard for motor skill performance. Motor development does not follow a rigid rule based on the progress of age, but age is only for a rough estimation of motor performance. Consequently, constructing curriculum based on age obviously against the dynamic approach in Dynamic System theory.

The word "dynamic" means the development is non-linear. It goes through all stages of motor skills, but not in a hierarchical order. (Gallahue, Ozmun \& Goodway, 2012). Stage in motor skills refers to a universal, sequential, and hierarchical appearance of movement, which also was ordered considering the principles of growth and development in children (Roberton, 1978). It is an estimation of the ability of children within a particular skill in certain age range. Dynamic allows children to go through stage three before stage two in motor skills. This dynamic process has been supported by Garcia and Garcia (2002) through their study in examining throwing development in children. In other words, development is a discontinued process and can be reordered. This dynamic mechanism is also due to individual factors, known as constraints. Constraints are categorized into two, which are factors that encourage the development, known as affordances, and factors that impede the development, called rate limiters (Gallahue, Ozmun \& Goodway, 2012). Affordances can be motivation, encouragement, positive feedback, and environment while rate limiters can be biology constraints (e.g. body shape, body mass index), environmental constraints (e.g. weather, seasons) and task constraints (e.g. static and moving target).

The term "system" describes that the development involves an individual organism organized by various subsystems (Gallahue, Ozmun\& Goodway, 2012). This biological self-organizing system is a result of adaptation to the environment yielding a movement behavior. Therefore, the development cannot be linear because it is dependent on the individual biology, the tasks and the environment which differ from one another. Kamm, Thelen, \& Jensen (1990) emphasize that system within a body lead children to a particular movement that they are able to do. However, the experiences that children have during their play activities adapt their body to develop and progress their motor skills. Kicking a ball for beginners, for instance, indicates that children have no balance to make a back swing of the kicking foot. Pushing movement of foot to kick a ball implies that children have lack balance in their body and lack of strength in their supporting foot, resulting inability to stand up with one foot over a long period of time. Hence, kicking a ball with a pushing action of their foot as quick as they can in order to get both feet back on the ground seems as a solution for children to prevent them from falling down. However, if children are stuck in this condition, their ability to kick will not evolve. Thus, through their motor skill programs, kicking activities would stimulate systems within their body, such as neuron, muscle strength and coordination systems, to thrive to be more mature.

Considering the essential of fundamental motor skills (FMS) supported by dynamic system theory, the motor developmentalists were inspired to design a specific program for promoting FMS by manipulating constrains in children environment (Deli, Bakle, \& Zachopoulou, 2006; Goodway \& Branta, 2003; Goodway, Crowe \& Ward, 
2003). It is believed that experiencing many gross motor skill practices would allow the maturation and development in children's movement system biologically, including large and small muscles, nervous and circulation system. Moreover, FMS would open a wide range of opportunity for children to be physically active outside and socialize with their peers. It will help children to promote their self-esteem and their perception about their potential. Under those circumstances, FMS is useful to promote not only their motor, but also another domain of their development, such as cognitive function and social function, which are useful for their entire life.

\section{Suggestions for Indonesia's Elementary School Physical Education Curriculum}

Motor skills develop along with children's body growth and development. Hence, it is highly essential to understand the principle of growth to design an appropriate motor skill program or lesson plans at schools. Feldman (2008) explains that growth follows four main principles, which are cephalocaudal (from head to toes), proximodistal (from center to the outward of the body), hierarchical integration (from simple to complex skills) and the independence systems (various rate of growth in body system). These four principles should be basic guidance for educators and experts in designing and implementing a better program for children. Therefore, some suggestions with regard to the elementary school physical education curriculum is given considering the four basic principles of motor development.

Cephalocaudal principle states that upper body would mature earlier than lower body. This principle serves as a guidance that elementary school physical education should be design by working on the upper body first before the lower body. For instance, during teaching striking skill, which children should have a multi-limb coordination between hand and foot, it is suggested that lesson plan should begin working in correcting hand before foot. In general, children for lower grade in elementary schools might have a larger portion of time for upper limb intervention lesson plan than lower limb one. Yet, it does not mean that while working with upper body limb, we are not allowed to work with the lower body extremities. What a program designer should care is the focus in the program should follow the growth pattern of children. While working with upper extremities, the lesson plan enables to begin with giving stimulation for lower body ability.

One of implementation of the proximodistal principle is related to gross and fine motor skill development. FMS provide a mechanism to develop large muscle to support gross motor skills as well as small muscles to support fine motor skills. Based on the principle of proximodistal, which explains that the development progress from the center to the outer of body (Feldman, 2008), children would be maturely developed in their trunk before their extremities. Further, their arms should develop prior the development of their finger. As an illustration, in the beginning stage of catching, children catch a ball by using their arms, by hugging or scooping the ball then followed by catching ball using their hand (Gallahue, 1987). These stages imply that their muscle around their hand and fingers have not developed yet while children perform novice stage and evolve to well-developed muscles in later stages. These progressive stages clearly depicts that using hand in catching comes at more mature stages, indicating that the development of hands occur after the arms; developing center of the body is preceded by outward of body. Even though, children do not experience those skills orderly, they would develop their capability to catch the ball based on their body readiness and the exercise. In addition of this principle, children need time to be able to figure out the spatial awareness. In early childhood, since the senses of peripheral of the body have not matured yet, children have difficulties in estimating the distance. This limitation restricts them to execute any movement smoothly. They often failed when they are running or striking. That is why little children learn striking by using a short bat to help them to judge their distance gradually.

Skill themes method introduced by Graham, Holt/Hale, \& Parker (2007) is a method to plan developmentally appropriate lesson plans for students, which obviously implement the hierarchical integration principle. All motor skills are taught from pre control to proficiency level sequentially begin from simple task to more complex task. Changing the target from stationary to a moving target is one example of how to manipulate the task in lesson plans. Children would focus only with their movement technique in stationary target. On the contrary, they should be able to combine their movement technique with their vision, eye-foot/hand coordination and balance in moving target. The sequence of teaching skill based on this principle is supported by Gallahue (1987). $\mathrm{He}$ describes the developmental teaching progression chart for both fundamental movement skills and sport-related movement skills that concomitant with hierarchical integration principle.

The independence of systems, as the last principle of growth, explains that each system within a body would grow in the different rate (Feldman, 2008). Payne and Isaacs (2008) depict that the proportion of children's body would vary from early childhood to late childhood that can impact their motor performance. During early childhood, their top of the body is larger than their low body. This top-heavy proportion influences their balance 
that leads them to have a high guard through hands and arms keep up while they are moving. Moreover, Payne and Isaacs (2008) add the explanation that during the adolescence, children experience the widening of shoulder and hip that influences their motor performance, such as running. Even, children would decline some of their motor ability due to those changes in their body. Related to these phenomena, teachers and coaches have to have pay attention much more to prevent injuries or regression of body performance in children.

Based on the four main principle of growth, curriculum of physical education in schools should promote children's growth and development along with their motor performance. It is suggested that curriculum of physical education is designed comprehensively from the lower grade to higher in elementary schools based on those four principle. Begin with upper body, center area of body, and simpler tasks, then progress to lower and outward of the body as well as more complex movement tasks. Furthermore, the usage of equipment in motor skills program should along with those principles, for instance, the length of equipment should be proportional with the growth of children. Shorter equipment is more appropriate for lower grade elementary students than longer equipment. However, so far, the authors have not found any studies that explicitly describe the usage of principle of growth as a frame theory for research. It may be assumed that researchers may have implemented more than one theory as the framework and explained only the main theory, even though they also integrated the principle of growth into their program. Misconception in designing the program or lesson plan may trigger a disaster for children, such as bad experiences in exercising or even the deviation in body development. Nonetheless, a developmentally appropriate program would lead the improvement of children's growth and motor development, and motivation to be engaged in sports, as well.

\section{Conclusion}

For the most part, data from The Ministry of Sports and Youth of Indonesia advises Indonesia to examine physical education curriculum and motor skills program for children. It is understood that a misconception in teaching motor skills during elementary schools would affect the participation of adolescence in sports, resulting the decline of sport achievement. The combination of dynamic system theory and four principles of growth guide physical education teacher, educator and coach to design motor skills program more developmentally appropriate to ensure children improve their motor skills. An appropriate motor skill program would result children who adroit in their basic movement skills can implement their skills in sport-related movement easily. If this mechanism ran as it should be, the coaching training department would be easier to find out some talented-competence children to be trained as elite athletes. Moreover, for those who have no willingness to be athletes, their motor proficiency would be beneficial skills for them to keep their life health and fit. Eventually, more population is expected to be more physically active in their life span.

\section{References}

Allender, S., Cowburn, G., \& Foster, C. (2006). Understanding Participation in Sport and Physical Activity among Children and Adults: A Review of Qualitative Studies. Health Education Research, 21(6), 826-835. http://dx.doi.org/10.1093/her/cyl063

Barnett, L. M., Morgan, P. J., E, V. B., Ball, K., \& Lubans, D. R. (2011). A Reverse Pathway? Actual and Perceived Skill Proficiency and Physical Activity. Medicine \& Science in Sports \& Exercise, 1. http://dx.doi.org/10.1249/MSS.0b013e3181fdfadd

Barnett, L. M., Van, B. E., Morgan, P. J., Brooks, L. O., \& Beard, J. R. (2008). Does childhood motor skill proficiency predict adolescent fitness? Medicine and Science in Sports and Exercise, 40(12), 2137-2144. http://dx.doi.org/10.1249/MSS.0b013e31818160d3

Deli, E., Bakle, I., \& Zachopoulou, E. (2006). Implementing intervention movement programs for kindergarten children. Journal of Early Childhood Research, 4(1), 5-18. http://dx.doi.org/10.1177/1476718X06059785

Draper, C. E., Achmat, M., Forbes, J., \& Lambert, E. V. (2012). Impact of a community-based programme for motor development on gross motor skills and cognitive function in preschool children from disadvantaged settings. Early Child Development and Care, 182(1), 137-152. http://dx.doi.org/10.1080/03004430.2010.547250

Feldman, R. S. (2008). Development across the life span (5th ed.). Upper Saddle River, NJ: Pearson/Prentice Hall.

Gallahue, D. L. (1987). Developmental physical education for today's elementary school children. New York: Macmillan.

Gallahue, D., Ozmun, J. C., \& Goodway, J. D. (2012). Understanding Motor Development: Infants, Children, 
Adolescents, Adults (7th ed.). New York: McGraw-Hill Companies, Inc.

Garcia, C., \& Garcia, L. (2002). Examining developmental changes in throwing. In J. E. Clark, \& J. H. Humphrey (Eds.), Motor Development: Research and Review (Vol. 2, pp. 62-95). Reston, VA: NASPE Publications.

Goodway, J. D., \& Branta, C. F. (2003). Influence of a Motor Skill Intervention on Fundamental Motor Skill Development of Disadvantaged Children. Research Quarterly for Exercise and Sport, 74(1), 36-46. http://dx.doi.org/10.1080/02701367.2003.10609062

Goodway, J. D., \& Rudisill, M. E. (1996). Influence of a motor skill intervention program on perceived competence of at-risk african american preschoolers. Adapted Physical Activity Quarterly, 13(3), 288-301.

Goodway, J. D., Crowe, H., \& Ward, P. (2003). Effects of motor skill instruction of fundamental motor skill development. Adapted Physical Activity Quarterly, 20(3), 298.

Graham, G., Holt/Hale, S. A., \& Parker, M. (2007). Children moving: A reflective approach to teaching physical education. New York: McGraw-Hill.

Hamilton, M., Goodway, J., \& Haubenstricker, J. (1999). Parent-assisted instruction in a motor skill program for at-risk preschool children. Adapted Physical Activity Quarterly, 16(4), 415-426.

Hands, B., Larkin, D., Parker, H., Straker, L., \& Perry, M. (2009, October 1). The relationship among physical activity, motor competence and health-related fitness in 14-year-old adolescents. Scandinavian Journal of Medicine \& Science in Sports, 19(5), 655-663. http://dx.doi.org/10.1111/j.1600-0838.2008.00847.x

Kamm, K., Thelen, E., \& Jensen, J. L. (1990). A dynamical systems approach to motor development. Physical Therapy, 70(12), 763-775.

Martin, E. H., Rudisill, M. E., \& Hastie, P. A. (2009). Motivational climate and fundamental motor skill performance in a naturalistic physical education setting. Physical Education \& Sport Pedagogy, 14(3), 227-240. http://dx.doi.org/10.1080/17408980801974952

Payne, V. G., \& Isaacs, L. D. (2008). Human motor development: A lifespan approach. Boston: McGraw-Hill.

Roberton, M. A. (1978). In M. V. Ridenour (Ed.), Motor development: Issues and applications. Princeton, N.J: Princeton Book Co.

Stodden, D. F., Goodway, J. D., Langendorfer, S. J., Roberton, M. A., Rudisill, M. E., Garcia, C., \& Garcia, L. E. (2008, May 1). A Developmental Perspective on the Role of Motor Skill Competence in Physical Activity: An Emergent Relationship. Quest, 60(2), 290-306. http://dx.doi.org/10.1080/00336297.2008.10483582

The Ministry of Sports and Youth of Indonesia. (2010). Penyajian Data \& Informasi Statistik Keolahragaan, 2010. Jakarta.

Valentini, N., \& Rudisill, M. (2004). Motivational climate, motor-skill development, and perceived competence: Two studies of developmentally delayed kindergarten children. Journal of Teaching in Physical Education, 23(3), 216-234.

\section{Copyrights}

Copyright for this article is retained by the author(s), with first publication rights granted to the journal.

This is an open-access article distributed under the terms and conditions of the Creative Commons Attribution license (http://creativecommons.org/licenses/by/3.0/). 